\title{
金属アルコキシドから合成したスェライト粉末の 分散性に関する研究
}

\author{
笠井紀宏・成田直人・尾崎義治 \\ (成蹊大学工学部工業化学科, 180 東京都武蔵野市吉祥寺北町 3-3-1)
}

\section{Study on the Dispersion of Alkoxy-Derived Ferrite Powders}

\author{
Toshihiro KASAI, Naoto NARITA and Yoshiharu OZAKI \\ $\left(\begin{array}{l}\text { Department of Industrial Chemistry. Faculty of Engineering Seikei University } \\ \text { 3-3-1, Kichijoji-kitamachi, Musashino-shi, Tokyo } 180\end{array}\right)$
}

The dispersion of fine magnetic powders synthesized from metal alkoxides was studied. The powders were treated with an alkali, and then oleic ions were adsorped in sodium oleate aqueous solution. This as-wetted powders were dispersed in water or alkylnaphthalene containing a surfactant. It is concluded that;

(1) Fine particles below 10-15 $\mathrm{nm}$ are required to prepare stable suspensions,

(2) To be fully adsorped with oleic ions, the powder synthesized have to be treated with an alkali,

(3) The surfactant more than 25 wt\% of the powder is repuired to disperse the powder,

(4) The effective surfactant is sodium oleate for water suspension medium and ethoxylated alcohol phosphate for alkylnaphthalene suspension medium.

[Received June 15, 1987 ; Accepted August 25, 1987]

Key-words : Metal alkoxide, Alkoxy-derived powder, $\mathrm{CoFe}_{2} \mathrm{O}_{4}, \mathrm{MnFe}_{2} \mathrm{O}_{4}$, Stable suspension, Surfactant

\section{1. 緒言}

微粒の強磁性粉末を分散媒中に安定に分散させた磁性 流体は見掛け上, 液体磁石のように挙動し, その応用は 磁性インク, 磁気シールなど無限に広がっている ${ }^{11}$. 製 法についても多くの報告がなされており ${ }^{2) ~ 3)}$, 特に下飯 坂らの行った水中でフェライト粒子の周りにオレイン酸 イオンを吸着させ, それを界面活性剤を含む分散媒中に 再分散させる分法 ${ }^{3)}$ は磁性流体の容易な製法として知ら れている．磁性流体はその用途によって種々の性質のも のが必要とされる. 金属アルコキシドを加水分解して得 られる粒子は粒径が小さいことが知られている4),5). 本 報告は, 金属アルコキシド法によって合成した強磁性粉 末を原料として磁気インクなどの用途を目的とした水を 分散媒とする磁性微粒子分散系, 磁気シールなどの用途 を目的とする高沸点液体を分散媒とする分散系の調製に 関するものである. 本研究では強磁性粉末としてコバル トフェライト, マンガンフェライト, 分散媒として水, アルキルナフタリン $(R=20)$ を対象とした. また, 粉 末の分散方法は下飯坂らの方法 ${ }^{3)}$ で行った.

\section{2. 実験方法}

\section{1 試料の調製}

$3 \mathrm{~A}$ のモレキュラーシーブスを用いて 24 時間脱水を 行った市販特級のエタノールを還流しておき, そこに市 販特級の $\mathrm{FeCl}_{3}$ 及び $\mathrm{MnCl}_{2}$ 又は $\mathrm{CoCl}_{2}$ を溶解させた.
$\mathrm{FeCl}_{3}$ は使用前に $50^{\circ} \mathrm{C}, \mathrm{MnCl}_{2}$ と $\mathrm{CoCl}_{2}$ は $200^{\circ} \mathrm{C}$ で 1 時間真空乾燥を行い無水物とした。そこに化学量論量の 金属ナトリウムを少量ずつ加えて反応させ, $\mathrm{Fe}-\mathrm{Mn}$ 又 は Fe-Co 混合アルコキシドを合成した。別に用意した 水一エ夕ノール混合溶液 $(50 \mathrm{vol} \%)$ を $70^{\circ} \mathrm{C}$ 程度に加熱 して, 上記混合アルコキシド溶液に還流下, 少量ずつ加 えて加水分解させマンガンフェライト又は, コバルト フェライトを合成した。ここまでの操作は $\mathrm{Mn}(\mathrm{II})$ 及 び $\mathrm{Co}$ ( II ) の酸化を防ぐために $20 \mathrm{cc} / \mathrm{min}$ の $\mathrm{N}_{2}$ ガスを 流し, 反応系を $\mathrm{N}_{2}$ 䨌囲気として行った. また $\mathrm{FeCl}_{3}$ の 代わりに $200^{\circ} \mathrm{C}$ で 1 時間真空乾燥を行った $\mathrm{FeCl}_{2}$ を用 いて，上記の操作によって混合アルコキシドを合成し， 加水分解後, エアレーションによる酸化を行って合成し たフェライトも比較のため実験に用いた．得られたフェ ライトからエタノールと副生成物の $\mathrm{NaCl}$ を乾燥工程を 加えることなしに除去するため, 加水一かくはんーデカン テーションという操作を繰り返した. その後, 沈降物に 種々の量の $\mathrm{NaOH}$ 水溶液を加えて, $80^{\circ} \sim 100^{\circ} \mathrm{C}$ で 30 $\min$ 加熱を行った. 放冷後, 加水一かくはんーデカンテー ションという操作を繰り返して系の $\mathrm{pH}$ を 8 9 程度に 下げた。そこにフェライトの理論収量に対して $30 \mathrm{wt} \%$ のオレイン酸ナトリウムを加えて $90^{\circ} \sim 95^{\circ} \mathrm{C} て ゙ ~ 30 \mathrm{~min}$ 加熱かくはんした.その後, 遠心分離を行い沈降物を種々 の方法によって分散媒である水又は，アルキルナフタリ ン中に添加して分散させた. その際, 界面活性剤として 


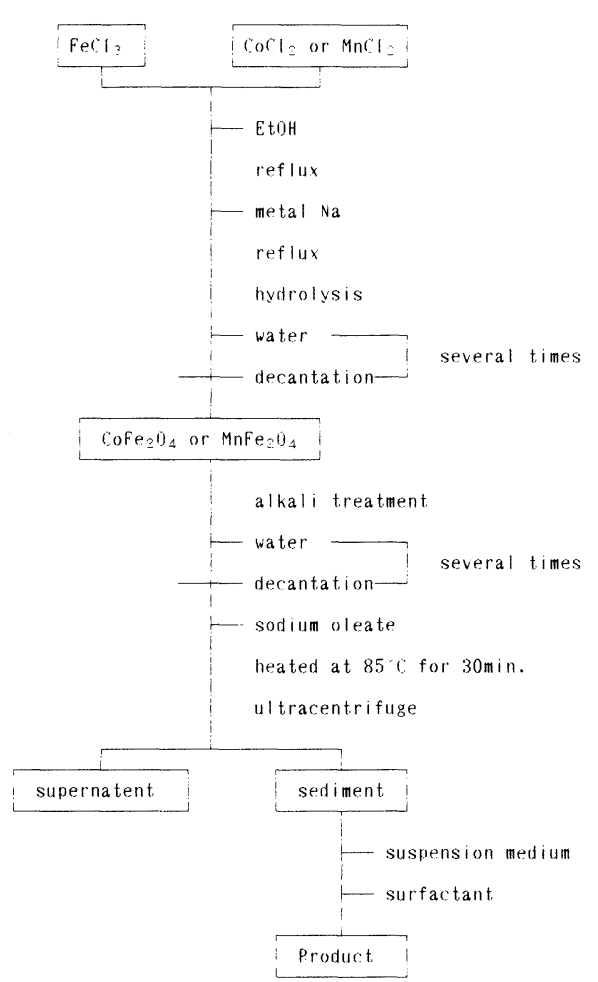

Fig. 1. The flowsheet for synthesis of ferrites suspensions.

水系ではオレイン酸ナトリウム, アルキルナフタリン系 では種々の市販の界面活性剤をフェライトの理論収量に 対して $30 \mathrm{wt} \%$ 加えた. また分散媒量は得られる分散系 の固体含有率が $25 \mathrm{wt} \%$ となるようにした。 ただし，水 分散系については調製した分散系を 24 時間静置させ, 大きな粒子を沈降させた. 図 1 に操作のフローシートを 示す.

\section{2 合成粉末のキャラクタリゼーション}

合成した粉末のキャラクタリゼーションはX 線回折 分析及び電子顕微鏡観察, 及び EDX 分析によって行っ た. X 線回折分析に用いた装置は理学電機製 RAD-IA 型粉末 $\mathrm{X}$ 線回折計であり $\mathrm{Cu} K \alpha$ 線（モ)クロメーター 使用）を用いて印加電圧 $40 \mathrm{kV}, 20 \mathrm{~mA}$ の条件で分析し た。電子顕微鏡観察は日本電子製の JEM-100 CX II を 用いて行った。

\section{3 分散安定性の評価}

水分散系に対しては, 図 2 に示すように $0.37 \mathrm{~T}$ の磁 石を分散液の入ったパイレックス製容器 (16.5 mm $\phi$, 高さ $45 \mathrm{~mm}$, 肉厚 $1 \mathrm{~mm}$ ) に数秒間接触させ, 接触部の 容器内面での磁性粉末の凝集の有無で分散性を評価し た. 粉末の凝集が起こらなかったものに対しては, 磁場 をかけずに 24 時間静置させ分散液を一定量分取した。 それを $70^{\circ} \mathrm{C}$ で乾燥し, 更に $1000^{\circ} \mathrm{C}$ で仮焼して, 固体 含有量を求めることによって評価した.

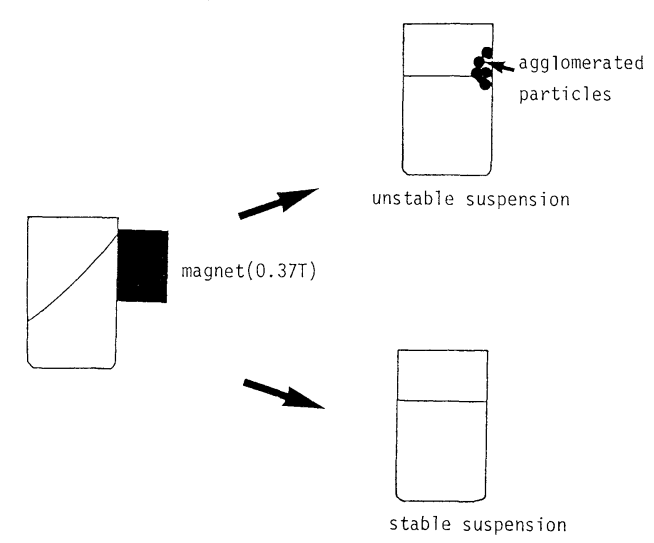

Fig. 2. The stability evaluation method of aqueous magnetic suspension.

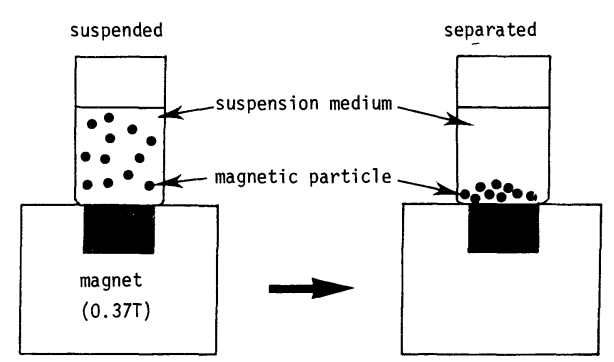

Fig, 3. The stability evaluation method of suspension with alkylnaphthalene medium.

アルキルナフタリン中に分散した系に対しては図 3 に 示すように分散液を $2 \mathrm{ml}$ を上記の容器に入れ, $0.37 \mathrm{~T}$ の磁石上に静置して, 上部液面で固体-液体分離が生じ るまでの時間を計ることによって評価した．すなわち， 分散している粒子が磁石に引きよせられ，液面上部に分 散媒である透明なアルキルナフタリンが出てくるまでの 時間を計り評価した。

\section{3. 結果及び考察}

3.1 合成粉末のキャラクタリゼーション

$\mathrm{Mn}-\mathrm{Fe}$ (III) 混合アルコキシドの加水分解によって得 られた粉末を, 水洗後, $70^{\circ} \mathrm{C}$ で乾燥させたものの $\mathrm{X}$ 線 回折パターンを, $\mathrm{Fe}$ (II ) を原料として合成したマンガ ンフェライトのものとともに, 図4に示し, それらの透 過型電子顕微鏡 (TEM) 写真を, 図 5 に示す。図 4 か ら分かるように $\mathrm{Fe}$ (II) を原料として合成したものの方 が結晶性が高いことが分かる. 更に, 図 5 から $\mathrm{Fe}$ (II ) を原料として合成したマンガンフェライト粒子は粒径が 20〜50 nm であるのに対して Fe(III) を原料として合成 したフェライトの粒子径は 10～15 nm と小さいことが 分かる. コバルトフェライトについても同様な結果で あった。これは $\mathrm{Fe}$ ( III) アルコキシドを用いた場合，原 料の混合アルコキシドは溶液として存在するのに対し 
(A)

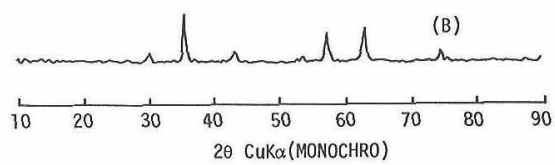

Fig. 4. X-ray diffraction patterns of $\mathrm{MnFe}_{2} \mathrm{O}_{4}$ powders synthesized from (A) mixed alkoxide of $\mathrm{Mn}$ (II) and $\mathrm{Fe}(\mathrm{III})$ and (B) mixed alkoxide of $\mathrm{Mn}(\mathrm{II})$ and $\mathrm{Fe}$ (II ).
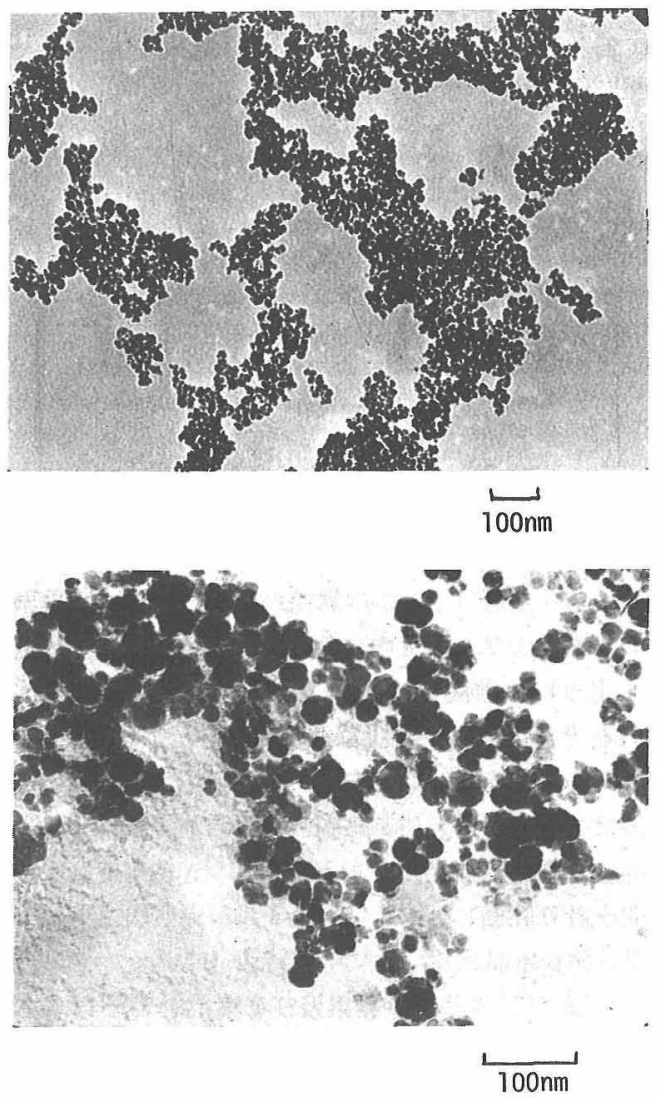

Fig. 5. Transmission electron micrographs of $\mathrm{MnFe}_{2} \mathrm{O}_{4}$ particles synthesized from (A) mixed alkoxide of $\mathrm{Mn}$ (II ) and $\mathrm{Fe}$ (III) and (B) mixed alkoxide of $\mathrm{Mn}(\mathrm{II})$ and $\mathrm{Fe}(\mathrm{II})$.

て， $\mathrm{Fe}$ (III) アルコキシドを使用した場合，固体として 存在する。そのため，加水分解で生成する粒子の大きさ はアルコキシド粒子の大きさに依存して大きなものとな ると考えられる. 磁性流体の合成において $15 \mathrm{~nm}$ 以下 の粒径の粉末が必要であることが報告されている1)。し たがって，安定な分散系を得るためには，Fe(III) を原 料しして合成したフェライト粒子の方が適していること が分かる。

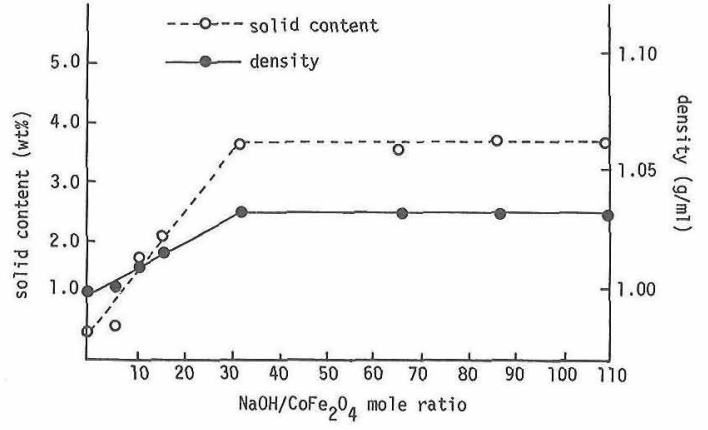

Fig. 6. The effect of $\mathrm{NaOH}$ on solid content and density of the $\mathrm{CoFe}_{2} \mathrm{O}_{4}$ suspension.

\section{2 分散性に対するアルカリ処理の効果}

図 6 はアルカリ処理に用いた $\mathrm{NaOH}$ 量とコバルト フェライトに水分散系の分散性の関係を示したものであ る。破線は分散液の固体含有率を示し，実線は分散液の 密度を示している．分散系の密度は全容ピペットで分取 したものの重さを計ることによって求めた，図から分か るように $\mathrm{NaOH} / \mathrm{CoFe}_{2} \mathrm{O}_{4}$ のモル比が約 30 以下では分 散性が悪く, 30 以上では固体含有率, 密度, 共に変わ らないことが分かる。これより安定な分散系を調製する ためには，コバルトフェライトに対してモル比で 30 以 上の $\mathrm{NaOH}$ が必要であることが分かった。これはアル カリ処理が粒子表面を改質させ，続くオレイン酸イオン 吸着処理におけるオレイン酸イオンの粒子表面への吸着 を容易にするためと考えられる。すなわち，粒子の $\mathrm{NaOH}$ 処理によって粒子表面の電気二重層中の $\mathrm{Na}^{+}$濃 度は增加する。この処理によって吸着された $\mathrm{Na}^{+}$イオ ンは, その後の加水-かくはん-デカンテーション処理に よって減少するが，それは拡散二重層の $\mathrm{Na}^{+}$イオンで あり, Stern 層中の $\mathrm{Na}^{+}$イオンは表面に強く吸着されて いるため，その $\mathrm{Na}^{+}$濃度はほとんど变化せず， $\mathrm{NaOH}$ 処理に続くオレイン酸处理ではオレイン酸イオンがこの Stern 層中の $\mathrm{Na}^{+}$イオンを介して強く吸着されるものと 思われる. $\mathrm{Fe}$ (II) と $\mathrm{Co}$ (II ) を原料として合成したコ バルトフェライトはアルカリ量にかかわらず安定な分散 系を調製することができなかった。これは得られる粒子 の大きさが大きいことに起因すると思われる．また，マ ンガンフェライトについても同様な結果が期待できると 思われる.

\section{3 分散性に対するオレイン酸ナトリウム量の効果}

図 1 に示す実験操作において，初めに加えるオレイン 酸ナトリウム量は，下飯坂らによって報告されていると おり，フェライト粉末に対して $30 \mathrm{wt} \%$ とした ${ }^{3)}$.ここ では，コバルトフェライトの水分散系に対して，再分散 時のオレイン酸ナトリウム量について，検討を行った。 図7にオレイン酸ナトリウム量とコバルトフェライトの 


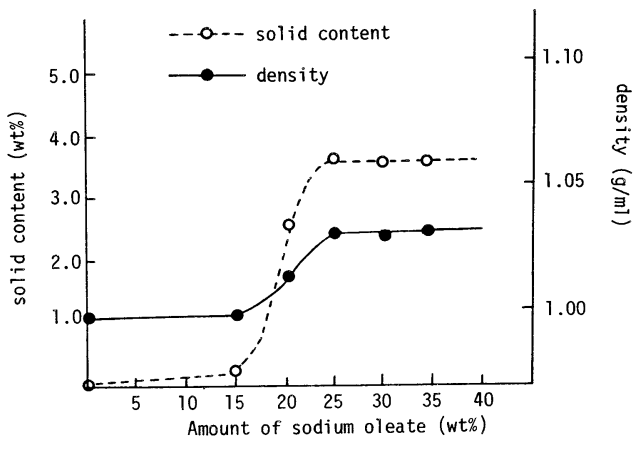

Fig. 7. The effect of sodium oleate on solid content and density of the $\mathrm{CoFe}_{2} \mathrm{O}_{4}$ suspension.

水分散系の分散性の関係を示す. 破線は分散時の固体含 有率を示し, 実線は分散液の密度を示している. 図 7 よ り，オレイン酸ナトリウム量がコバルトフェライトに対 して $25 \mathrm{wt} \%$ までは固体含有率も分散液の密度も低く, $25 \mathrm{wt} \%$ 以上からそれらはほとんど一定となっている. これより, 分散時にはオレイン散ナトリウムはコバルト フェライト量に対して $25 \mathrm{wt} \%$ 以上必要であることが分 かった. $\mathrm{Fe}$ ( II ) と $\mathrm{Co}$ (II ) を原料として合成したコバ ルトフェライトはオレイン酸ナトリウム量にかかわらず 安定に分散しなかった。 また, この結果より分散媒にア ルキナフタリンを用いた場合についても界面活性剤量は 粉末に対して $25 \mathrm{wt} \%$ 以上とした。

\section{4 界面活性㓮の影響}

先に述べたように水分散系の調製で用いた界面活性剂 はオレイン酸ナトリウムのみとした。ここでは，アルキ ルナフタリンを分散媒とする場合の界面活性剤について 検討を行った．実験に用いた界面活性剂之得られた分散 系の安定性を表 1 に示す．表から分かるようにアルコー ルエトキシレートのリン酸エステルである旭電化製の界 面活性剤 PS-810 E を用いたものは他のものと比較し て極めて良好な分散状態を示した。しかし，PS-810 E を用いて合成した磁性流体においても長時間磁場をかけ ると, 固液分離は生じなかったが磁石に近い部分で少量 の粒子凝集が観察された。本実験で磁性超微粒子の安定 な分散を得るために行った方法は，単純なかくはんのみ であり，今後分散処理法，界面活性剂を検討することに より更に分散性を向上させることが期待できると思わ れる. また， Fe(II) を原料として合成したフェライト は界面活性剂の種類にかかわらず安定に分散しなかっ た。

\section{5 脱水方法の検討}

オレイン酸吸着処理は水中で行われているため，オレ イン酸吸着後の粒子は水を多量に含んでいる．水分散系 に対しては分散媒が水であるため，そのまま分散させる ことができる。しかし，アルキルナフタリンを分散媒と
Table 1. The relation between surfactants and the solid-liquid separation time of suspension under the magnetic field.

\begin{tabular}{|c|c|c|}
\hline Surfactant & $\begin{array}{l}\text { Solid-i iqu } \\
\text { time under } \\
\text { magnetic f }\end{array}$ & $\begin{array}{l}\text { quid separation } \\
\text { er } 0.37 T \text { of } \\
\text { fieid (hr.) }\end{array}$ \\
\hline glycerol mono-oleate & 0.5 & $\sim 0.75$ \\
\hline $00 \mathrm{P}^{1}$ & 0.5 & $\sim 0.75$ \\
\hline$F S-7030^{1}$ & 0.05 & $\sim 0.25$ \\
\hline$F Z-431 D^{!}$ & 0.05 & $\sim 0.25$ \\
\hline$F Z-4320^{1}$ & 0.05 & $\sim 0.25$ \\
\hline Idekaestol oEG-106: & & $\sim 0.5$ \\
\hline Rheodol SP-0 10 & 1 & $\sim 2$ \\
\hline Rheodol SP-i $30^{3}$ & & $\sim 0.5$ \\
\hline Rheodol TW-0 $106^{3}$ & 0.5 & $\sim 1$ \\
\hline Rheodol TW-10 $320^{\circ}$ & & $\sim 0.5$ \\
\hline Emalex $P c_{i}-d i-0^{4 r}$ & 0.5 & $\sim 1$ \\
\hline Emalex $\mathrm{PGO}^{4}$ & 0.5 & $\sim 1$ \\
\hline$T 0-106^{5}$ & 1 & $\sim 2$ \\
\hline TAMNO $-2^{5}$ & 0.5 & $\sim 1$ \\
\hline$W-915^{z}$ & & $\sim 0.5$ \\
\hline$W-918^{2}$ & & $\sim 1$ \\
\hline$W-934^{2}$ & & $\sim 0.3$ \\
\hline$P S-810 E^{2 \prime}$ & 48 & $\sim$ \\
\hline $\mathrm{CS}-1361 \mathrm{E}^{2}$ & & $\sim 0.3$ \\
\hline $5 x-811^{2}$ & & $\sim 0.05$ \\
\hline $5 x-812^{2}$ & & $\sim 0.16$ \\
\hline$S x-980^{2}$ & & $\sim 0.13$ \\
\hline $\begin{array}{l}\text { 1) from } \\
\text { 2) from } \\
\text { 3) from } \\
\text { 4) from } \\
\text { 5) from }\end{array}$ & $\begin{array}{l}\text { LION CORP. } \\
\text { ASAHI DENK } \\
\text { KAO CORP. } \\
\text { NIHON EMUL } \\
\text { NIKKOU CHE }\end{array}$ & $\begin{array}{l}\text { NKA KOUGYOU K.K } \\
\text { ULSION Corp. } \\
\text { HEMICALS Corp. }\end{array}$ \\
\hline
\end{tabular}

する場合，粉末中に含まれる水が不純物となる，そのた めアルキルナフタリン中に加えてからの脱水処理が必要 よなる。ここでは脱水方法について検討を行った．本実 験で検討した脱水方法は以下の 5 方法である。

（a）水を含有したフェライトをアルキルナフタリン 中に加えて, 分散後 $70^{\circ} \mathrm{C}$ 程度に加温して脱水を行う。

（b）水を含有したフェライトをアルキルナフタリン 中に加えて, 分散後室温で真空乾燥を行い脱水を行う.

（c）水を含有したフェライトを $70^{\circ} \mathrm{C}$ で乾燥後，ア ルキルナフタリン中に加えて分散を行う.

（d）水を含有したフェライトを室温で真空乾燥後, アルキルナフタリン中に加えて分散を行う.

（e）水を含有したフェライトをメタノール洗浄と遠 心分離を繰り返してメタノール-粉末系とした後，アル キルナフタリン中に加えて分散後, $70^{\circ} \mathrm{C}$ で脱メタノー ルを行う.

それらの結果，(a) の方法ではアルキルナフタリンと 水が不混和であり, 更に水の比重がアルキルナフタリン より大きいので, 分散後水が磁性流体下部に分離する. そのため加温によって水の揮発が妨げられ完全な脱水は 困難であった. 
（b）の方法では界面活性剤の影響により乾燥中に突 沸が起こりやすく, 操作的に困難であった. (c), (d)の 方法では脱水が容易に行えたが, 乾燥後の粉末は安定に 分散しなかった.これは乾燥によって粒子が強い凝集を 起こすためと考えられる. (e) の方法ではメ夕ノ一ルが アルキルナフタリンと混和であるため（a）の方法と比 較して容易に脱水が達成され, た. また, 分散状態も (a) の方法で得られたものと同程度であった.これより脱水 方法として (e) の方法が有効であることが分かった.

\section{4. 総 括}

$\mathrm{Fe}$ (III) と $\mathrm{Mn}$ ( II ) 又は $\mathrm{Co}$ ( II ) の混合アルコキシド を加水分解して得られたマンガンフェライト及びコバル トフェライトを原料として, 水及びアルキルナフタリン を分散媒とする安定な分散系を調製することができた。 また，次のことが分かった。

（Ｉ）安定な分散系を得るためには, 粒径が 10〜15 $\mathrm{nm}$ 以下の微粒子粉末が必要であり, その要求に対して $\mathrm{Fe}$ ( III) と $\mathrm{Co}$ ( II ) の混合アルコキシドを還流下で加水 分解することによって合成されるフェライト粒子が適し ている.

（II）合成された粒子の周りにオレイン酸イオンの 1 次吸着層をつける必要があるが，そのためにフェライト
粒子を一度アルカリで処理して，粒子の表面改質を行う 必要がある。、

（III）オレイン酸を吸着させた粒子を水中に再分散さ せるため, 界面活性剤として粉末に対して $25 \mathrm{wt} \%$ 以上 のオレイン酸ナトリウムが必要であった。 また，アルキ ルナフタリン中に分散させるための界面活性剤としては PS-810 E が最良の結果を与えた。

（IV）安定分散系を調製する過程において，合成され た超微粒子をいったん乾燥させると安定な分散が達成さ れない.

（V） アルキルナフタリンを分散媒とする系におい て, 分散系からの脱水方法としては, メ夕ノール洗浄を 行いメタノール-粉末系とした後アルキルナフタリン中 に加えて分散させ，その後加温してメ夕ノールを除去す る方法が有効である.

\section{文献}

1）下飯坂潤三，日本金属学会会報，15，77-82（1976）。

2) S.S. Papell, U.S. Patent No. 3215572 (1965).

3）下飯坂潤三, 中塚勝人, 中鉢良治, 佐藤惟陽, 日本化学 会誌, 1976, 6-9 (1976).

4) K. S. Mazdiyasni, R. T. Dolloff and J. S. Smith, II, J. Am. Ceram. Soc., 52, 532-26(1969).

5）笠井紀宏, 山本章造, 尾崎義治, 窯協 95, 1000-06(1987). 